\title{
Initial density estimates of humpback whales Megaptera novaeangliae in the inshore waters of the western Antarctic Peninsula during the late autumn
}

\author{
D. W. Johnston ${ }^{1, *}$, A. S. Friedlaender ${ }^{1}$, A. J. Read $^{1}$, D. P. Nowacek ${ }^{1,2}$ \\ ${ }^{1}$ Division of Marine Science and Conservation, Nicholas School of the Environment, Duke University Marine Laboratory, \\ 135 Duke Marine Lab Rd., Beaufort, North Carolina 28516, USA \\ ${ }^{2}$ Pratt School of Engineering, Duke University, Durham, North Carolina 27708, USA
}

\begin{abstract}
In the Southern Ocean, humpback whales Megaptera novaeangliae were depleted by commercial whaling operations during the 20th century, but many populations now appear to be recovering. Previous surveys of whale distribution along the western Antarctic Peninsula (WAP) suggested that humpbacks feed on krill swarms over the continental shelf during the summer, but little is known about their movements and densities during autumn, when krill begin to seek inshore refugia for overwintering. Here we present estimates of humpback whale densities in some inshore regions of the WAP during the late autumn. We surveyed $653.9 \mathrm{~km}$ of track line in the Gerlache Strait and adjacent bays during 26 April to 1 June 2009. We detected 371 groups of humpback whales in a distance sampling framework that allowed us to calculate estimates of whale density along track lines in open and enclosed habitats within our study area. Density estimates along track lines ranged from 0.02 to 1.75 whales $\mathrm{km}^{-2}$; the highest densities were found along track lines in the enclosed regions of Wilhelmina Bay, the Errera Channel, and Andvord Bay. These results provide preliminary insight into the density and distribution of WAP humpbacks and indicate that large numbers of whales remain in Antarctic feeding grounds late into autumn. This study also provides details on the difficulties in estimating density of whales in the inshore regions of the WAP using traditional line transect/distance sampling methods, and provides direction for future studies including the use of model-based approaches to estimating whale densities in this region.
\end{abstract}

KEY WORDS: Humpback whale - Western Antarctic Peninsula $\cdot$ Density $\cdot$ Line transect

\section{INTRODUCTION}

Humpback whales Megaptera novaeangliae are a cosmopolitan baleen whale species that spend summers feeding at high latitudes and winters in low latitude regions for breeding (Johnson \& Wolman 1984). In the Southern Hemisphere, humpbacks migrate between feeding regions around the Antarctic continent (Laws 1977) and breeding grounds off Central America, South America, Oceania, Australia, New
Zealand, and Southern Africa (Kellogg 1929, Rayner 1940, Mackintosh 1942, Rasmussen et al. 2007).

Humpback whales were depleted throughout their range by intensive commercial harvests in the 20th century, but many populations now appear to be recovering (see Reilly et al. 2010). Humpbacks have been studied in their breeding regions in the Southern Hemisphere, with research focusing on reproductive behavior, population structure, and abundance (e.g. Garrigue et al. 2000). On the feeding 
grounds, broad-scale population assessment research efforts have been conducted around the Antarctic continent. Since the 1980s, several surveys have described summer densities of humpback whales in offshore and continental shelf waters around Antarctica (e.g. Kasamatsu et al. 2000), but little is known about the timing of migrations to breeding grounds, and very little survey effort has been directed at the inshore regions of the continent, especially during autumn. During the early 20th century, shore-based whalers exploited humpbacks in the inshore waters of the western Antarctic Peninsula (WAP), and this region still represents a significant foraging habitat for whales in the summer (Secchi et al. 2001), although the area has not been systematically surveyed later in the feeding season.

In the continental shelf waters of the WAP, humpback whales are the most common cetacean species (Secchi et al. 2001, Thiele et al. 2004, Friedlaender et al. 2006). Recent work at both broad and meso-scales has established that their distribution and occurrence patterns relate primarily to prey abundance and secondarily to other environmental variables (Friedlaender et al. 2006, 2009). One of the most important and dynamic features of the Antarctic marine ecosystem is the annual advance and retreat of sea ice, followed by an unprecedented gathering of upper trophic level predators that feed on Antarctic krill Euphausia superba (Laws 1977). During the summer months, humpback whales take advantage of swarms of krill distributed across the continental shelf (Murase et al. 2002), but little is known about humpback distribution and density in inshore waters later in the season.

Increased knowledge of the distribution and density patterns of these once depleted predators throughout their feeding season would provide insights into the structure and function of the Antarctic Peninsula marine ecosystem as it continues to warm. Furthermore, understanding how the distribution and density of humpback whales change throughout their feeding season in the WAP region will help optimize future population assessments and management strategies. Our study provides the first density estimates for humpback whales in nearshore regions of the WAP during late autumn.

\section{MATERIALS AND METHODS}

\section{Study location and timing}

We conducted visual line transect surveys for cetaceans from the ARSV 'Laurence M. Gould' in coastal waters of the central WAP (Fig. 1), between
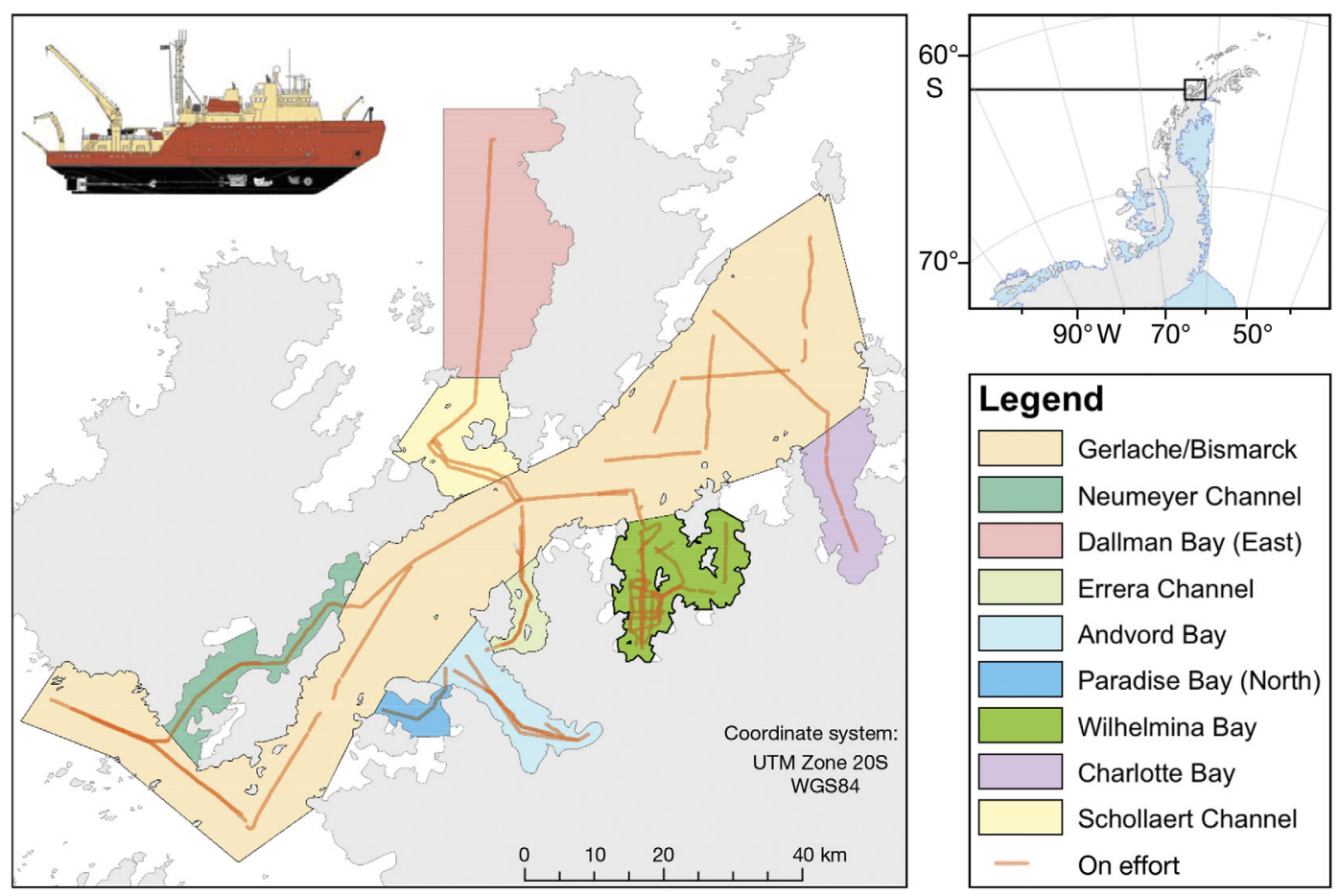

Fig. 1. Survey regions and visual survey effort in the Gerlache Strait, western Antarctic Peninsula, and nearby channels and bays in autumn 2009. A schematic of the survey vessel ARSV 'Laurence M. Gould' is shown in the upper left of the panel 
$64.150^{\circ}$ and $65.025^{\circ} \mathrm{S}$ latitude during 29 April to 1 June 2009. The ASRV 'Gould' is $76 \mathrm{~m}$ long, and its viewing platform on the bridge wings is $13 \mathrm{~m}$ above the water.

\section{Distance sampling}

Visual surveys were conducted along track lines within several discrete regions throughout the study area: Andvord Bay, Charlotte Bay, Dallman Bay (East), Errera Channel, Gerlache/Bismarck Strait, Paradise Bay (North), Schollaert Channel, and Wilhelmina Bay (Fig. 1). These track lines were based on safe passage rules established for the survey vessel, which could not travel at speeds greater than 3 knots $\left(5.5 \mathrm{~km} \mathrm{~h}^{-1}\right)$, unless the ship had previously traversed that particular route, and could not approach closer than $1 \mathrm{~km}$ to the shoreline. As such, we were unable to follow randomized track lines designed to optimize coverage probability. Instead, track lines generally followed the axis of each narrow bay or channel centrally (where ice and bathymetry allowed), except in areas of the Gerlache Strait, where several track lines followed a zigzag pattern along the axis of the strait, and in Wilhelmina Bay, where 2 sets of track lines were established. The first set of track lines in Wilhelmina Bay was designed to provide coverage perpendicular to the long axis of the bay, consistent with nighttime acoustic Doppler current profile (ADCP) surveys for krill mapping and oceanographic sampling during a larger ecological study of humpback whale foraging (Nowacek et al. 2011). A second set of track lines was surveyed to provide coverage parallel to the long axis of the bay. This pattern of sampling was designed to assess potential environmental gradients that could affect the density of whales occurring deeper into the bay. Each track line was treated as a sample of the survey region for density estimation. The on-effort sections of these track lines are presented in Fig. 1. Survey speeds ranged between 11 and $20 \mathrm{~km} \mathrm{~h}^{-1}$, and care was taken to avoid double counting whales during changes in speed and course by the survey vessel.

We used standard line transect methods (e.g. Barlow 2006) to collect radial distance, bearing, and group size of all species of cetaceans encountered. A group was considered as all whales within 3 body lengths of each other. Two observers (port and starboard) located on the bridge wings of the vessel (Fig. 1) scanned constantly from straight ahead to $90^{\circ}$ abeam, while a third observer recorded sighting and environmental data into a laptop computer running
VisSurvey (Version 1.0). This program was interfaced with the ship's global positioning system so that all sightings were geo-referenced and time-stamped. Observers recorded the amount of ice cover (as a percentage) within a $1 \mathrm{~km}$ strip of the vessel every $30 \mathrm{~min}$, or whenever it changed. Bearings to sightings were estimated with the aid of azimuth guides taped to the ship's railing. The restricted viewing ranges within the surveyed bays and passages made the use of binocular reticules impossible for rapid distance measurements. As such, distances to each cue were estimated by observers and were then assessed for bias post hoc; any systematic distance estimation bias was determined for individual observers by comparing true distances to objects in the water determined with a laser range-finder for observer estimates for the same objects (Williams et al. 2007). This relationship was then used to reduce bias in observer distance estimates for further density estimation.

\section{Density estimation}

Density estimation was conducted using the program Distance (Version 6.0, see Thomas et al. 2010) using the Multiple Covariate Distance Sampling (MCDS) analysis engine, which allowed us to account for the effects of sea state and ice cover on detection probabilities (Thomas et al. 2010). Encounter rate, expected cluster size, and density were estimated by region (stratum) within 2 separate analyses based on the type of habitat surveyed, i.e. open (large open straits and bays such as the Gerlache Strait) and enclosed (narrow fjords, channels, or embayments such as Wilhelmina Bay). Each analysis used a detection function generated for all sightings within that habitat type. A global density for each habitat type was calculated for the study period using the mean of strata estimates weighted by the total effort in each stratum, with strata treated as replicate samples for the habitat type. Both continuous sea state and ice cover were included as potential covariates in the detection function model for each analysis. To address any potential effects of cluster size on density estimation, we regressed the $\log$ of cluster size against the proportion of animals present that are detected at distance $x$ from the trackline, $g(x)$, and employed the size bias regression estimator if expected cluster size was significantly different than mean cluster size of observations $(\mathrm{p}<$ 0.05 ). The need for truncation of the largest distances of sightings was explored separately for each habitat type, similar to the by-species treatment conducted 
by Williams \& Thomas (2007). We considered detection functions fitted to datasets that had truncation distances rounded up by $\sim 500 \mathrm{~m}$ increments inwards of the largest observed distance. For density estimation, the program considered models at a selected truncation distance with half-normal and hazard rate key detection functions, and adjustment terms were selected automatically. We calculated encounter rate variance using the quasi-Poisson method with an overdispersion factor of 2 as recommended by Burnham et al. (1980).

\section{Perception and availability biases}

Distance sampling methods assume that all animals on the track line are detected, but this assumption is rarely met with marine mammal surveys (Buckland et al. 2001). Two forms of bias are associated with this assumption: availability bias, where animals are not available for detection on the track line because they are underwater; and perception bias, where animals are available for detection but missed because their presence was not perceived by the observer (Buckland et al. 2001). For the present study, we assumed that perception bias along the track line during surveys was insignificant, as survey conditions were optimal and the whales did not react to the presence of the boat until it was very close, providing ample opportunity for observers to detect them.

We assessed the availability bias of humpback whales in our study region using surface and dive times of humpback whales determined by concurrent tagging experiments with digital recording tags (Dtags, see Johnson \& Tyack 2003). For marine mammal line transect surveys, the probability of availabil- ity at the surface is determined by the amount of time the animals spend at the surface and the 'viewing window' in time from the survey vessel, $w(x)$. The viewing window of any survey is determined by the speed of the survey vessel and range within which observers are searching for and detecting groups of individuals. These relationships were quantified by Barlow (1988) using a model where observers search forward from a vessel moving at some velocity $(\mathrm{V})$ within a square viewing area with length $r$.

The dive records of tagged whales from the study area were examined to determine the average subsurface time $\left(E_{\mathrm{d}}\right)$ and surface interval $\left(E_{\mathrm{s}}\right)$ for whales during visual survey hours, as well as the maximum dive time recorded for tagged whales during this period $\left(\mathrm{d}_{\max }\right)$. Using these data, and the viewing window calculated above, the probability of availability of humpback whales for the present survey can be calculated using Eq. (1), derived by Laake et al. (1997) and modified by Paxton et al. (in press):

$$
P(\text { available })=\frac{E_{\mathrm{s}}}{E_{\mathrm{s}}+E_{\mathrm{d}}}+\frac{\left(w(x) \times E_{\mathrm{d}} / E_{\mathrm{s}}+E_{\mathrm{d}}\right)}{\mathrm{d}_{\max }}
$$

where $0<w(x)<\mathrm{d}_{\max }$

\section{RESULTS}

\section{Survey effort and sightings}

Geographic representations of survey effort, track lines, and humpback whale sightings for each region in the study area are presented in Fig. 1 and Table 1. Along with humpback whales, 4 other cetacean species were also detected during surveys: Antarctic minke whales Balaenoptera bonarensis $(\mathrm{n}=23)$,

Table 1. Megaptera novaeangliae. Survey effort and density estimates of humpback whales in the Gerlache Strait and nearby channels and bays during the autumn of 2009. na: not applicable, CV: coefficient of variation

\begin{tabular}{|c|c|c|c|c|c|c|c|c|}
\hline Stratum & $\begin{array}{l}\text { Habitat } \\
\text { type }\end{array}$ & $\begin{array}{l}\text { Effort } \\
(\mathrm{km})\end{array}$ & $\begin{array}{l}\text { Track } \\
\text { lines }\end{array}$ & Sightings & $\begin{array}{l}\text { Encounter } \\
\text { rate }\left(\mathrm{km}^{-1}\right)\end{array}$ & $\% \mathrm{CV}$ & $\begin{array}{c}\text { Density } \\
\text { (no. ind. } \mathrm{km}^{-2} \text { ) }\end{array}$ & $\% \mathrm{CV}$ \\
\hline Dallman Bay (East) & Open & 34 & 1 & 2 & 0.59 & 100.00 & 0.02 & 100.90 \\
\hline Gerlache/Bismarck Strait & Open & 270 & 11 & 72 & 0.27 & 16.70 & 0.09 & 20.60 \\
\hline Open overall & Open & 304 & 12 & 74 & na & na & 0.08 & 20.00 \\
\hline Andvord Bay & Enclosed & 80 & 6 & 58 & 0.72 & 18.60 & 0.68 & 19.28 \\
\hline Charlotte Bay & Enclosed & 19 & 1 & 2 & 0.11 & 100.00 & 0.10 & 100.10 \\
\hline Errera Channel & Enclosed & 15 & 2 & 27 & 1.75 & 27.20 & 1.64 & 27.70 \\
\hline Neumeyer Channel & Enclosed & 36 & 2 & 1 & 0.03 & 141.40 & 0.03 & 141.50 \\
\hline Paradise Bay (North) & Enclosed & 12 & 1 & 5 & 0.43 & 63.30 & 0.46 & 63.50 \\
\hline Schollaert Channel & Enclosed & 38 & 2 & 6 & 0.15 & 63.30 & 0.15 & 58.00 \\
\hline Wilhelmina Bay & Enclosed & 134 & 19 & 251 & 1.87 & 8.93 & 1.75 & 10.30 \\
\hline Enclosed overall & Enclosed & 333 & 33 & 350 & na & na & 1.00 & 9.20 \\
\hline
\end{tabular}


southern right whales Eubalaena australis $(\mathrm{n}=2)$, Btype killer whales Orcinus orca $(\mathrm{n}=4)$, and Arnoux's beaked whales Berardius arnuxii $(\mathrm{n}=2)$. The locations of these sightings are presented in Fig. 2. We surveyed a total of $653.9 \mathrm{~km}$ of track line across both open and enclosed habitats, producing 371 on-effort detections of groups of humpback whales used in density estimation calculations. Viewing conditions during much of the survey were excellent. Most survey effort $(70 \%)$ was conducted in regions with no ice, and half of the survey effort $(50 \%)$ was conducted in Beaufort sea state conditions of 0 . The percentages of survey effort conducted under varying sea state and ice conditions are presented in Fig. 3.

\section{Observer distance estimation performance}

As seen in other experiments assessing observer distance estimation performance (e.g. Williams et al. 2007), the relationship of estimated distances to actual distances measured using a laser range-finder was linear on a log-log scale. We regressed $\log _{\text {actual }}$ versus $\log _{\text {estimated }}$ distances $(n=68)$ to determine the extent of bias introduced. One observer consistently underestimated distances across all ranges $\left(\mathrm{r}^{2}=95 \%\right.$, $\left.\log _{\text {estimated }}=0.8928217 \times \log _{\text {actual }}\right) ;$ this observer's estimates were corrected separately from the rest of the observers. When regressed, the remaining observer data were largely homoscedastic and best described by: $\log _{\text {estimated }}=1.031 \times \log _{\text {actual }}\left(r^{2}=76 \%\right)$. These relationships were then used to correct for bias in estimated distances for further analysis.

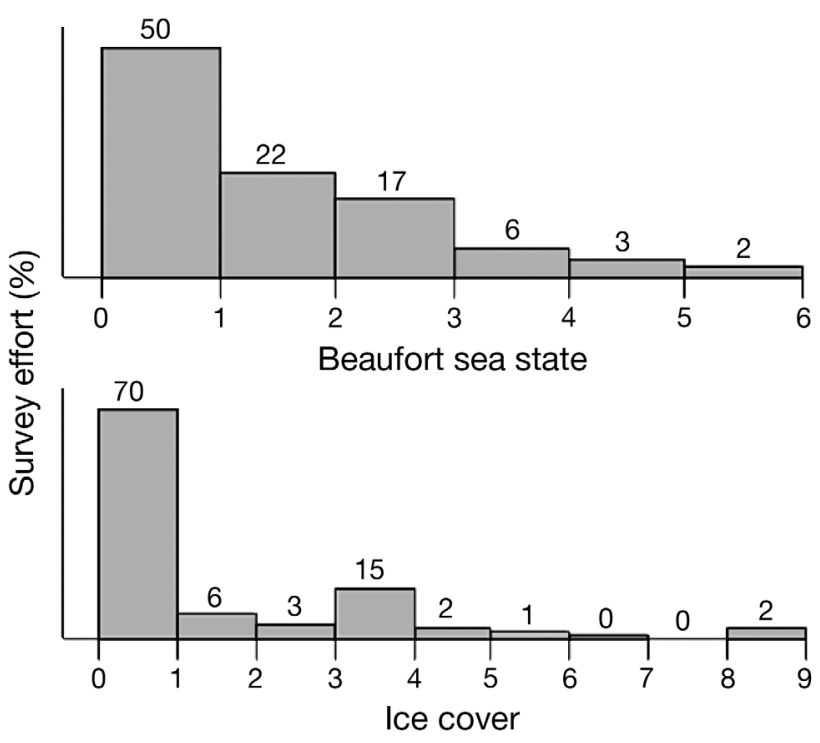

Fig. 3. Distributions of survey effort (\%) conducted in various Beaufort sea state and ice cover conditions during line transect surveys in open and enclosed habitats of the inshore western Antarctic Peninsula region in autumn 2009

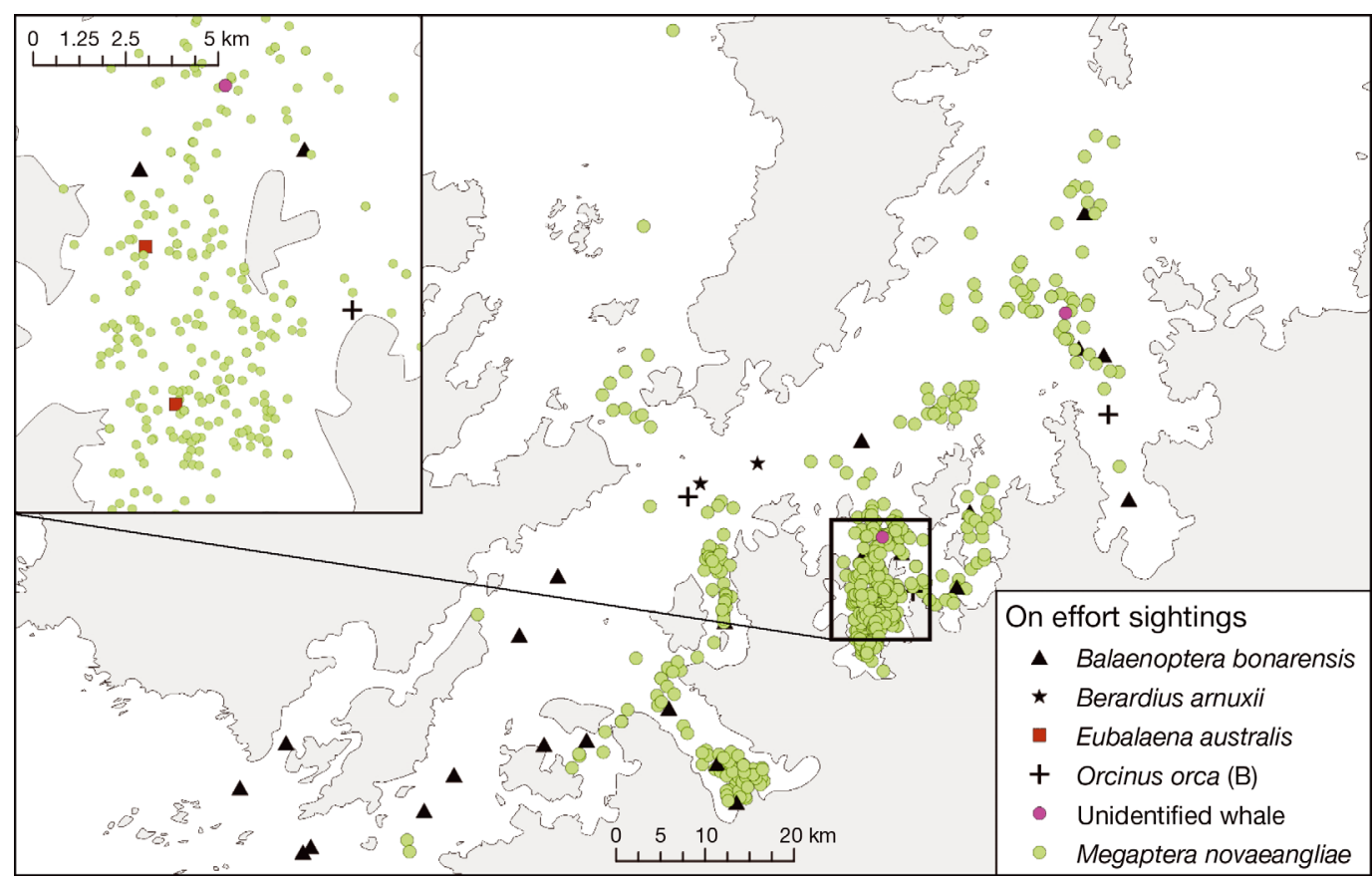

Fig. 2. Sightings of cetaceans detected on line transect surveys in the Gerlache Strait and nearby channels and bays in autumn 2009 


\section{Availability bias calculations}

Eleven humpback whales were tagged with Dtags during the survey period, and the average subsurface, surface, and maximum dive times for each individual whale are presented in Table 2 . These data were used to calculate the probability of availability of whales in the study region as per Eq. (1) above. Considering the average survey speed of $13 \mathrm{~km} \mathrm{~h}^{-1}$ and the viewing distance of $2.5 \mathrm{~km}$, the availability of animals on the track line was 1.0. Our density estimates therefore did not require adjustment for animals missed on the track line.

\section{Distance analysis and density estimates}

The numbers of samples and observations for all strata within both open and enclosed habitats are presented in Table 2. Size bias regressions for both open and enclosed habitats indicated that expected cluster size was not significantly different than mean cluster size $(p<0.05)$. Thus, the mean cluster size was used for both analyses.

For the open habitat analysis, the data were not truncated, and the MCDS analysis engine considered 2 half-normal models and 2 hazard rate models, with the final model chosen by the minimum Akaike information criterion (AIC). The final open habitat model used a half-normal key function with both ice cover and sea state as covariates and did not require any adjustment terms. The calculated effective strip

Table 2. Megaptera novaeangliae. Constant dive times and surface intervals of humpbacks tagged with digital recording tags in the Gerlache Strait and nearby channels and bays during the autumn of 2009

\begin{tabular}{|lccc|}
\hline $\begin{array}{l}\text { Whale } \\
\text { ID }\end{array}$ & $\begin{array}{c}\text { Mean surface } \\
\text { (s) }\end{array}$ & $\begin{array}{c}\text { Mean dive } \\
\text { (s) }\end{array}$ & $\begin{array}{c}\text { Max dive } \\
\text { (s) }\end{array}$ \\
\hline Mn121a & 974 & 190 & 298 \\
Mn122a & 84 & 83 & 298 \\
Mn122b & 72 & 325 & 696 \\
Mn127a & 757 & 194 & 539 \\
Mn127b & 547 & 166 & 447 \\
Mn128a & 107 & 210 & 446 \\
Mn136a & 786 & 429 & 725 \\
Mn140a & 261 & 209 & 602 \\
Mn148a & 137 & 68 & 292 \\
Mn151a & 205 & 205 & 395 \\
Mn151a & 151 & 85 & 375 \\
Mean & 408 & 216 & 474 \\
SE & 108 & 33 & 51 \\
Maximum & 974 & 429 & 725 \\
\hline
\end{tabular}

width was $2269.4 \mathrm{~m}(\% \mathrm{CV}=9.69)$. The average detection function for all ice and sea state conditions in open habitat is presented in Fig. 4A.

For the enclosed habitat analysis, the selected truncation distance was $2500 \mathrm{~m}$, and the MCDS analysis engine considered 3 half-normal models and 2 hazard rate models with the final model chosen by the minimum AIC. The final enclosed habitat model used a half-normal key function with 2 cosine adjustments and both ice cover and sea state as covariates. The calculated effective strip width was $948.8 \mathrm{~m} \mathrm{( \% CV} \mathrm{=}$ 4.25). The average detection function for the enclosed habitat analysis is presented in Fig. 4B.

Density estimates for all open and enclosed habitat strata are presented in Table 1, along with

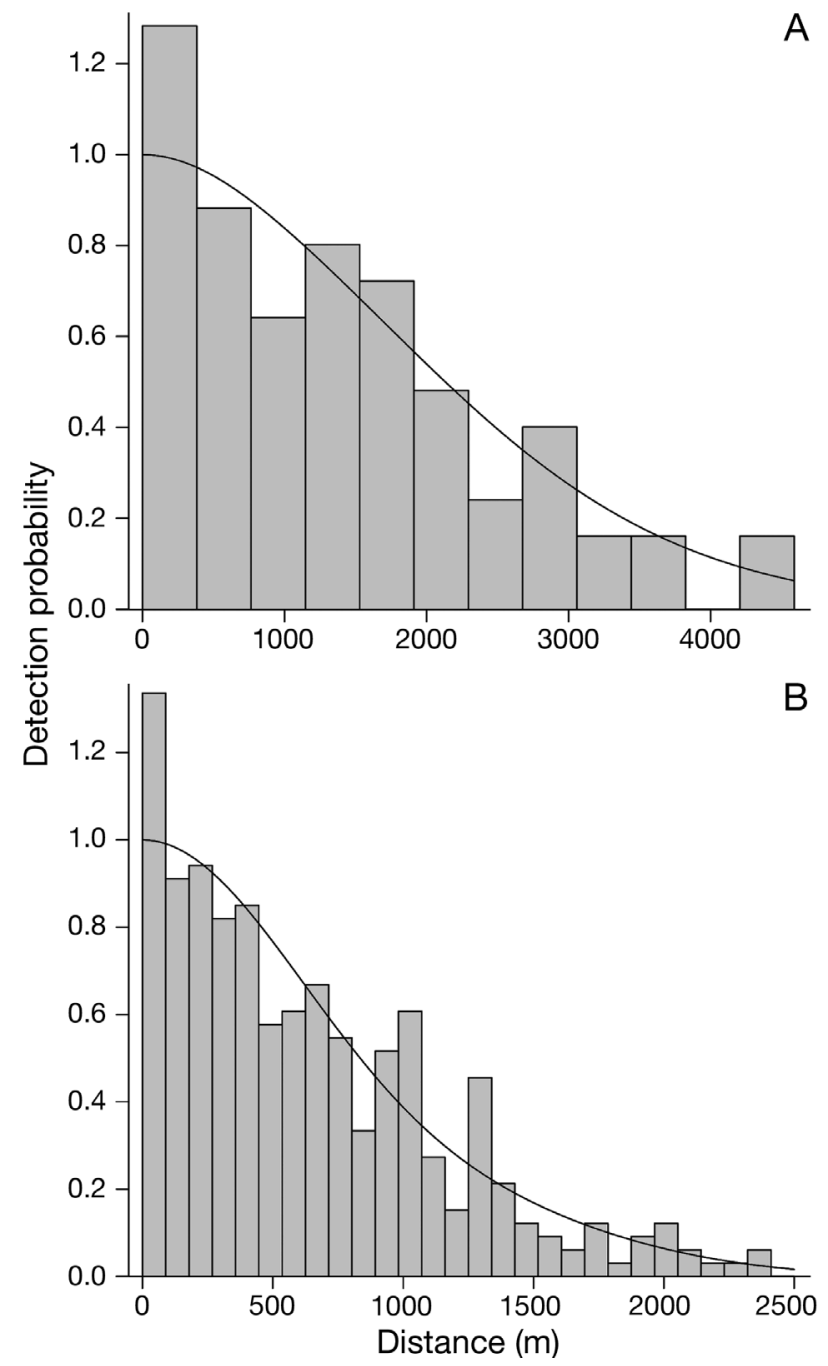

Fig. 4. Global detection functions for density analysis of humpback whale sightings generated during line transect surveys in (A) open and (B) enclosed habitats of the inshore western Antarctic Peninsula region in autumn 2009 
details on encounter rates and mean overall density estimates for each habitat type. Wilhelmina Bay had the greatest density of whales encountered in the inshore regions of the WAP, followed by the Errera Channel, Andvord Bay, Paradise Bay (North), Schoellart Channel, the Gerlache Strait, Charlotte Bay, and Dallman Bay. Density of whales was significantly greater in enclosed habitat than in the open habitat of the Gerlache/Bismarck Strait and Dallman Bay.

\section{DISCUSSION}

Our results provide the first estimates of humpback whale density in the inshore waters of the WAP during autumn. In general, our results confirm that the inshore regions of the WAP are an important feeding location for humpbacks in the austral autumn and early winter.

Previous surveys in this region have been restricted largely to the more open waters of the Gerlache Strait and waters offshore of the peninsula. For example, Secchi et al. (2001) reported on surveys of the Gerlache Strait during 1998 to 2000 that produced encounter rates of individual whales ranging from 0.05 to $0.47 \mathrm{~km}^{-1}$. The only other available encounter rate data for this inshore region was compiled by Stone \& Hamner (1988). They sighted 103 humpbacks during $842 \mathrm{~km}$ of surveys across our study region, producing an overall encounter rate of 0.12 whales $\mathrm{km}^{-1}$. They also noted that whale densities appeared to be higher in bays when compared to the Gerlache Strait and that whales were more likely to be sighted within $4.6 \mathrm{~km}$ of shore. Our humpback density estimates and encounter rates support Stone \& Hamner's (1988) observations of increased humpback densities in small bays of the region and indicate that many humpback whales aggregate in these small bays and channels late in the austral autumn to forage on large krill swarms (see Nowacek et al. 2011). Our highest point estimate for density of humpback whales $\left(1.75 \mathrm{~km}^{-2}, \% \mathrm{CV}=10.3\right)$ was found in Wilhelmina Bay, and our lowest point estimates were found in the open habitats of the Gerlache Strait/Bismarck Strait and Dallman Bay (Table 1). A comparison of mean densities of humpback whales in both open and enclosed habitats reveals that the density of humpbacks in the enclosed habitats is dramatically higher than in open habitats (Table 1).

Previous research has established that the distribution of humpback whales along the WAP is strongly related to that of krill (Friedlaender et al. 2006). In fall, adult populations of krill appear to move inshore into deep coastal areas, where they overwinter in large aggregations, covered by advancing sea ice (Lascara et al. 1999). Juvenile and larval krill are thought to overwinter in close proximity to winter sea ice that may serve as both a refuge and food source during winter months (Nicol 2006). Based on the seasonal offshore-onshore movement of krill from summer to winter, the higher densities of whales found in the enclosed coastal bays and fjords inshore of the Gerlache Strait in our study likely reflect the last feeding aggregations of humpback whales along the WAP before they are forced from these areas by encroaching sea ice. Satellite-derived movement patterns of individual humpback whales around the Gerlache Strait from January to March (Dalla Rosa et al. 2008) show diverse residence times across the continental shelf and inshore areas of the WAP, and the final location of 1 tagged individual (tracked until 16 April) was indeed close to the continent, in the Biscoe Archipelago region approximately $170 \mathrm{~km}$ south of the central Gerlache Strait. Presumably, these and other whales would eventually become aggregated into near-shore bays (such as Wilhelmina Bay) following adult krill.

The number of humpback whales we detected in these bays in the late autumn raises questions about the timing and frequency of migratory movements to breeding regions by individual whales. If the Gerlache Strait region remains largely ice free in future winters, non-reproductive humpback whales could choose to remain close to large overwintering krill swarms and forego migration to lower latitudes. This phenomenon also occurs in humpback whales foraging on dense aggregations of Pacific herring in the inshore regions of southeastern Alaska (e.g. Straley 1990). Previous surveys in this area did not assess humpback densities in the bays of the WAP in late autumn, so conclusions about the timing of migrations to breeding areas by humpback whales feeding around the WAP (e.g. Kasamatsu et al. 2000, Secchi et al. 2001) may not capture the entirety of the behavior of this population.

The average group size of humpback whales generated by our density analysis in both open habitat $(1.57, \% \mathrm{CV}=5.86)$ and closed habitat $(1.77$, $\% \mathrm{CV}=2.96$ ) also bears mentioning. Similar group size estimates (2.04 individuals) were generated during surveys for humpbacks in the inshore regions of southeast Alaska during the autumns of 1991 to 2007 (Dahlheim et al. 2009). Early shorebased whalers operating in the WAP also noted this 
relationship (Tønnessen \& Johnsen 1982). These observations differ greatly from the average group size (17) of humpbacks recorded by Laidre et al. (2010) in West Greenland. The stability and social function of pairing in humpback whales found late on the feeding grounds in the WAP region remains largely unstudied.

\section{Biases and caveats}

Our study represents the first density estimates for humpback whales in the restricted bays and narrow passages of the inshore WAP in the austral autumn. These estimates should be viewed with some caution due to the complexities of conducting distance sampling in these areas, and our inability to follow track lines designed to provide unbiased and complete coverage of the study region. These potential biases and complexities are discussed below.

Due to the lack of visible horizon for almost all of our survey effort and the high density of whales, the standard use of binocular reticules or photogrammetry was impossible. We therefore relied on distance estimates from observers, corrected for bias. Several authors have illustrated why distance estimation is sub-optimal, but necessary, in situations where the horizon is unknown and it is impossible to assess distance to shore as a substitute. However, it appears that density estimation is relatively robust to errors in distance estimation, as long as they are not systematically biased (see Chen 1998 and Williams et al. 2007), and our bias corrections should address any significant issues. Indeed, because distance estimates by observers tend to overestimate actual distances to detected groups of whales, any residual bias in our density estimates would be negative (Williams et al. 2007), so our estimates of density should be considered conservatively low.

Due to safe-passage rules for the ship, our surveys could not follow track lines designed to provide equal probability of coverage across the study area. This is an important assumption for estimating densities and abundances using distance sampling techniques, and thus our density estimates may be biased and should be considered as preliminary. Due to this limitation, we present our data as densities along track lines in each survey region, as they may not be representative of overall densities in each stratum. In several cases, we were only able to traverse a single line down the center of narrow bays and channels. These types of track lines are sub-optimal for estimating abundance, as they may not capture spatial aggregations of whales influenced by proximity to the shore. Furthermore, some locations were only sampled once, and calculating proper variance for estimates in these cases is problematic. To overcome this, we calculated variance in encounter rates using a quasi-Poisson method as described by Burnham et al. (1980). This is not an ideal approach, but it does provide the ability to present preliminary density estimates across all portions of our study region as an informed null hypothesis for future studies.

One approach to avoid these issues, and assess the extent to which our estimates may be biased, is to compare them with a model-based approach to estimating density (e.g. Hedley \& Buckland 2004, Katsanevakis 2007), but this analysis is beyond the scope of this initial study. Model-based methods can deal with non-randomized survey designs that do not provide equal probability of coverage across the survey region and can provide fine-scale spatially explicit maps of density in complex coastal regions such as the WAP. This approach would help alleviate the need for survey designs that are essentially unachievable in the inshore regions of the WAP.

In one of our regions, Wilhelmina Bay, visual survey effort essentially covered the entire stratum along track lines designed to repeatedly cross both axes of the bay (e.g. multiple passes allowing sampling of all sections of the bay; see Thomas et al. 2007,) and it is likely that our analysis for this location approaches a robust estimation of abundance. In Wilhelmina Bay, our survey stratum was 25624 ha, and our analysis indicates that 401 humpbacks (CV $=13 \%$ ) were present in this bay during the study period. Furthermore, the comparison between density estimates of humpback whales in open and enclosed habitats is likely robust, as the survey approach and analysis is conserved between them.

Despite the caveats and the potential biases introduced by limitations in our sampling methods, the results of our surveys provide preliminary insights into the distribution and density of humpback whales at the presumed conclusion of the foraging season in the WAP. An improved understanding of the seasonal densities of these whales and their residency/ migration patterns will provide novel information regarding the ecological role of humpback whales in the rapidly warming Antarctic Peninsula region. Furthermore, the knowledge of this late season aggregating behavior can be used to refine survey efforts in the region and establish analytical methods to best determine the abundance of humpback whales in relation to prey densities and other environmental factors in the WAP region. 
Acknowledgements. We thank the officers, crew, and marine technicians of LM 'Gould' for their invaluable assistance, and visual observers L. Peavey, E. Revelli, and R. Tyson for their excellent work in the field. This manuscript was refined through the helpful comments of R. Williams and 3 anonymous reviewers. This research was conducted under NMFS MMPA Permit 808-1735 and Antarctic Conservation Act permit 2009-014, and was supported by the Office of Polar Programs through NSF grant number ANT07-39483.

\section{LITERATURE CITED}

Barlow J (1988) Harbor porpoise, Phocoena phocoena, abundance estimation for California, Oregon, and Washington: ship surveys. Fish Bull 86:417-432

Barlow J (2006) Cetacean abundance in Hawaiian waters estimated from a summer/fall survey in 2002. Mar Mamm Sci 22:446-464

Buckland ST, Anderson DR, Burnham KP, Laake JL, Borchers DL, Thomas L (2001) Introduction to distance sampling. Oxford University Press, Oxford

Burnham KP, Anderson DR, Laake JL (1980) Estimation of density from line transect sampling of biological populations. Wildl Monogr 72:1-202

Chen S (1998) Measurement errors in line transect surveys. Biometrics 54:899-908

> Dahlheim ME, White PA, Waite JM (2009) Cetaceans of southeast Alaska: distribution and seasonal occurrence. J Biogeogr 36:410-426

Dalla Rosa L, Secchi ER, Maia YG, Zerbini AN, HeideJørgensen MP (2008) Movements of satellite-monitored humpback whales on their feeding ground along the Antarctic Peninsula. Polar Biol 31:771-781

Friedlaender AS, Halpin PN, Qian S, Lawson GL, Wiebe PH, Thiele D, Read AJ (2006) Whale distribution in relation to prey abundance and oceanographic processes in shelf waters of the Western Antarctic Peninsula. Mar Ecol Prog Ser 317:297-310

Friedlaender AS, Lawson GL, Halpin PN (2009) Evidence of resource partitioning between humpback and minke whales around the western Antarctic Peninsula. Mar Mamm Sci 25:402-415

Garrigue C, Forestell P, Greaves J, Gill P, Naessig P, Patenaude NM, Baker SC (2000) Migratory movements of humpback whales (Megaptera novaeangliae) between New Caledonia, East Australia and New Zealand. J Cetacean Res Manag 2:111-116

Hedley SL, Buckland ST (2004) Spatial models for line transect sampling. J Agric Biol Environ Stat 9:181-199

Johnson MP, Tyack PL (2003) A digital acoustic recording tag for measuring the response of wild marine mammals to sound. IEEE J Oceanic Eng 28:3-12

Johnson J, Wolman A (1984) Humpback whale, Megaptera novaeangliae. Mar Fish Rev 46: 31-37

Kasamatsu F, Matsuoka K, Hakamada T (2000) Interspecific relationships in density among the whale community in the Antarctic. Polar Biol 23:466-473

Katsanevakis S (2007) Density surface modelling with line transect sampling as a tool for abundance estimation of marine benthic species: the Pinna nobilis example in a marine lake. Mar Biol 152:77-85

Kellogg R (1929) What is known of the migration of some of the whalebone whales. Smithson Inst Annu Rep 1928: 467-494

Laake JL, Calambokidis J, Osmek SD, Rugh DJ (1997) Probability of detecting harbor porpoise from aerial surveys: estimating $g(0)$. J Wildl Manag 61:63-75
Laidre KL, Heide-Jørgensen MP, Heagerty P, Cossio AM, Bergström B, Simon M (2010) Spatial associations between large baleen whales and their prey in West Greenland. Mar Ecol Prog Ser 402:269-284

Lascara C, Hofmann E, Ross R, Quetin L (1999) Seasonal variability in the distribution of Antarctic krill, Euphausia superba, west of the Antarctic Peninsula. Deep-Sea Res II 46:951-984

Laws R (1977) Seals and whales of the Southern Ocean. Philos Trans R Soc Lond B Biol Sci 279:81-96

Mackintosh NA (1942) The southern stocks of whalebone whales. Discov Rep 22:197-300

Murase H, Matsuoka K, Ichii T, Nishiwaki S (2002) Relationship between the distribution of euphausiids and baleen whales in the Antarctic $\left(35^{\circ} \mathrm{E}-145^{\circ} \mathrm{W}\right)$. Polar Biol 25: 135-145

Nicol S (2006) Krill, currents, and sea ice: Euphausia superba and its changing environment. Bioscience 56: 111-120

> Nowacek DP, Friedlaender AS, Halpin PN, Hazen EL and others (2011) Super-aggregations of krill and humpback whales in Wilhelmina Bay, Antarctic Peninsula. PLoS ONE 6:e19173

Paxton CGM, Hedley SL, Bannister JL (2011) Group IV humpback whales: their status from aerial and landbased surveys off Western Australia, 2005. J Cetacean Res Manag Spec Issue 3:223-234

> Rasmussen K, Palacios D, Calambokidis J, Saborio MT and others (2007) Southern Hemisphere humpback whales wintering off Central America. Biol Lett 3:302-305

Rayner GW (1940) Whale marking progress and results to December 1939. Disc Rep 19:245-284

Reilly SB, Bannister JL, Best PB, Brown M and others (2010) Megaptera novaeangliae. In: IUCN (2010). IUCN Red List of Threatened Species. Version 2010.4. Available at www.iucnredlist.org (accessed 2 May 2011)

Secchi ER, Dalla Rosa L, Kinas PG, Santos MCO, Zerbini AN, Bassoi M, Moreno IB (2001) Encounter rates of whales around the Antarctic Peninsula with special reference to humpback whales (Megaptera novaeangliae), in the Gerlache Strait: $1997 / 98$ to $1999 / 2000$. Mem Queensl Mus 47:571-578

> Stone GS, Hamner WM (1988) Humpback whales Megaptera novaeangliae and southern right whales Eubalaena australis in Gerlache Strait, Antarctica. Polar Rec 24:15-20

Straley JM (1990) Fall and winter occurrence of humpback whales (Megaptera novaeangliae) in southeastern Alaska. Rep Int Whal Comm Spec Issue No. 12, p 319-323

Thiele D, Chester E, Moore SE, Sirovic A, Hildebrand JA, Friedlaender AS (2004) Seasonal variability in whale encounters in the Western Antarctic Peninsula. DeepSea Res II 51:2311-2325

Thomas L, Williams R, Sandilands D (2007) Designing line transect surveys for complex survey regions. J Cetacean Res Manag 9:1-13

Thomas L, Buckland ST, Rexstad EA, Laake JA and others (2010) Distance software: design and analysis of distance sampling surveys for estimating population size. J Appl Ecol 47:5-14

Tønnessen JN, Johnsen AO (1982) The history of modern whaling. C. Hurst and Co., London

Williams R, Thomas L (2007) Distribution and abundance of marine mammals in the coastal waters of British Columbia, Canada. J Cetacean Res Manag 9:15-28

Williams R, Leaper R, Zerbini AN, Hammond PS (2007) Methods for investigating measurement error in cetacean line-transect surveys. J Mar Biol Assoc UK 87: 313-320

Submitted: May 6, 2010; Accepted: October 17, 2011

Proofs received from author(s): July 25, 2012 